\title{
Exploring association between gastrointestinal heat retention syndrome and recurrent respiratory tract infections in children: a prospective cohort study
}

Fei Dong ${ }^{1+}, \mathrm{He} \mathrm{Yu}^{1+}$, Jiaju Ma ${ }^{1,2}$, Liqun Wư ${ }^{3}$, Tiegang Liu', Guokai Lv ${ }^{1,4}$, Jianhua Zhen ${ }^{1}$, Xiaofei Li', George Lewith ${ }^{5}$ and Xiaohong $\mathrm{Gu}^{1 *}$

\begin{abstract}
Background: Recurrent respiratory tract infections (RRTIs) have a negative impact on both children's health and family wellbeing. Deficiency of ZhengQi used to be an instinct factor driving RRTI in Traditional Chinese Medicine (TCM). Our clinical observations suggest that children with gastrointestinal heat retention syndrome (GHRS) may have a greater risk of catching respiratory tract infections (RTIS). GHRS is a new predisposing factor for RRTI and it is dietary related. This study is aimed to explore association between GHRS and RRTI.

Methods: A prospective cohort study has been conducted in Beijing, China; children aged 1-18 were enrolled. TCM symptoms, demographic and physiological characteristics were recorded by using semi-structured questionnaire. GHRS was considered as a predisposing factor. Children were followed up for next 12 months. We contacted with their parents using a face-to-face questionnaire survey, via email or phone every 3 months. Episodes of RTls were recorded in detail.

Results: Three hundred thirty four children were enrolled and 307 (91.92 \%) followed up for 12 months. The incidence of RTI was 4.32 episodes per child-year ( $95 \%$ Cl 4.03-4.61). 69 (43.13\%) children in the group with GHRS suffered from RRTI; there were 48 (32.65\%) children in group without GHRS. The risk ratio (RR) value of RRTI occurrence was 1.32 (95\% Cl 0.91-1.91, $P=0.139$ ), and the attributable risk percent (AR\%) was $24.28 \%$. Dry stool and irritability were positively correlated with RTI episodes, age and BMI were negatively correlated with RTI episodes in a linear regression model. Dry stool $(\mathrm{OR}=1.510)$ was positively correlated with $\mathrm{RRTI}$ occurrence, age $(\mathrm{OR}=0.889)$ and $\mathrm{BMI}(\mathrm{OR}=0.858)$ were negatively correlated with RRTI occurrence in our logistic regression model.

Conclusions: GHRS is associated with RRTI in this cohort. Dry stool was positively associated with RRTI, and BMI was negatively associated with RRTI. Studies with larger sample size and longer follow up are needed to further evaluate this association. Relieving GHRS should be considered when TCM practitioners treat RRTI children, and this may protect children from suffering RTIs.
\end{abstract}

Trial registration: Chinese Clinical Trial Registry Number: ChiCTR-CCH-13003756

Keywords: Gastrointestinal heat retention syndrome, Recurrent respiratory tract infection, Children, Prospective cohort study

\footnotetext{
* Correspondence: guxh1003@126.com

${ }^{\dagger}$ Equal contributors

${ }^{1}$ School of Basic Medical Science, Beijing University of Chinese Medicine,

Beijing, China

Full list of author information is available at the end of the article
}

\section{$\int$ Biomed Central}

(c) 2016 Dong et al. Open Access This article is distributed under the terms of the Creative Commons Attribution 4.0 International License (http://creativecommons.org/licenses/by/4.0/), which permits unrestricted use, distribution, and reproduction in any medium, provided you give appropriate credit to the original author(s) and the source, provide a link to the Creative Commons license, and indicate if changes were made. The Creative Commons Public Domain Dedication waiver (http://creativecommons.org/publicdomain/zero/1.0/) applies to the data made available in this article, unless otherwise stated. 


\section{Background}

Respiratory tract infection (RTI) is a major cause of morbidity and mortality worldwide especially in lowand middle-income countries. RTIs are common in children and significantly contribute to pediatric morbidity and mortality [1]. Lower respiratory tract infections (LRTI) (pneumonia predominantly) is one of the leading causes of death in infants and children, especially in developing countries. Approximately 2 million children who die from acute respiratory tract infections (ARTIs) each year [2, 3]. ARTI is the most prevalent in children in primary care: $50 \%$ of children aged $0-4$ are diagnosed with ARTI and $10 \%$ of those aged 5-9 [4]. The true incidence of the condition in community may be much higher as usually parents do not consult their doctors when their children develop an upper respiratory tract infection (URTI) [4].

Recurrent respiratory tract infection (RRTI) is a common disease with a higher morbidity both in winter and spring, especially for children [5]. Data suggested $30 \%$ RTIs children suffer from RRTIs, and the morbidity from RRTI in children is increasing [6]. Wenjie $\mathrm{Xu}$ and Weihong Liu surveyed children aged from 3 to 6 years in Chaoyang District and Pinggu District of Beijing, China, and found that the morbidity of RRTIs in these regions were 17.8 and $18.7 \%$ [7, 8]. RRTIs impact on children's health and present significant problems for their families. The economic and social impacts of these infections constitute important challenges to public health because of treatment costs hospitalization, school absenteeism, and loss of working days by parents and caregivers [9].

Many studies have explored the causes of RRTI in children. Generally speaking, recurrent or persistent respiratory infection is suggestive of a deficiency in local or systemic host defenses or an underlying pulmonary disorder which may result from structural, functional or environmental causes [10]. This may include malnutrition such as Vitamin A or serum iron and zinc deficiencies, environmental pollution with heavy metals and an allergic history as well as maternal health during pregnancy $[7,11,12]$. Immune status also impacts on children's resistance to pathogenic microorganisms [12].

RRTI is deemed to result from congenital and acquired factors, such as deficiency of kidney Qi, lack of proper postnatal care, hypofunctioning of spleen and stomach from the point of view of Traditional Chinese Medicine (TCM) [6]. People with lung, spleen and kidney deficiency are liable to cause exogenous pathogens, thus have more risk to suffer from RRTI. In 2008, there are four different kinds of TCM deficiency syndromes which are declared as the classification of syndromes for the infantile RRTI [5]. However, the constitution and clinical characteristics of children in China have changed along with the life quality and environment. Therefore, we wished to consider new TCM models to explain the pathogenesis of RRTI besides of deficiency of ZhengQi [13-16].

Research work from our team identified that improper diet or eating habits could injure people's health [13]. This may present as dry mouth, foul breathing, epistaxis, gingivitis, aphthous ulcers, a feverish feeling in the palms and soles, intolerance to heat and sweating. TCM theory reveals that an unhealthy diet which is rich in sugar, protein, energy, salt or additives will do harm to children' health, while that may be easier to be accessible than before, and they are difficult to digest completely by children, finally end up with dyspepsia as well as the symptoms as above [17]. We defined all these symptoms as gastrointestinal heat retention syndrome (GHRS) based on TCM syndrome differentiation.

GHRS is a syndrome that is associated with increased gastrointestinal heat caused by a metabolic block in energy [17]. Symptoms are involved in including intolerance to heat, excess sweating, dry mouth, a preference for cold drinks desire, foul breath, swift digestion with increased apatite, excessive eye gum, nasal scabs, epistaxis, gingivitis, aphthous ulcers, skin rash, a feverish feeling in the palms and soles, irritability, sleep-talking, bruxism, yellow urine, dry stool, constipation, smelly stools and a reddened tongue with yellow fur. A GHRS diagnosis scale is used to identify people with or without GHRS [18].

Studies have shown that the incidence of functional constipation is $5-10 \%$ in pediatric outpatient clinic [19]. Infantile constipation mostly results from excessive water absorption by the colon, which may be influenced by poor nutrition [20]. Functional constipation in children is often accompanied by internal heat caused by indigestion [21]. The lung and the large intestine are interior-exteriorly related from the point of view of TCM [22]. Studies showed that patients with severe intestinal dysfunction were vulnerable to acute respiratory infections, while facilitating excretion of feces may help to achieve a better outcome for RTIs associated with constipation [23-26]. Studies have revealed that lung and stomach have been closely related, and GHRS could impact the lung function whether with or without RRTI [25].

Previous clinical observations suggested that children with GHRS might have a greater risk of catching RTIs, and experiment studies showed that mice with GHRS were more severely affected after catching FM1 virus infection than the control group from our team work [27]. Our primary aim was to explore the association between GHRS and RRTI in children to identify strategies that could improve patient outcome and prevent RRTI. This study also aimed to supplement the TCM etiology that suggests deficiency of ZhengQi is an instinct factor 
driving RRTI. We also aimed to describe the morbidity of RRTI in children and explore which disease-related and socio-demographic factors were associated.

\section{Methods \\ Design of study}

This is a prospective pragmatic cohort study in secondary care. Participants were enrolled into group with GHRS and group without GHRS according to whether they had GHRS or not, which was used as the 'exposure factor'. Symptoms of GHRS, disease-related and socio-demographic factors were recorded by using semi-structured questionnaire. We contacted with participants' parents using face-to-face questionnaire survey, via email or phone every 3 months. The incidence of RTI was recorded over the next 12 months to investigate the association between GHRS and RRTI.

We calculated the sample size with $\alpha$ (significance level $)=0.05$, Power $(1-\beta)=0.90$ and $\mathrm{P}($ overall event rate $)=$ 0.8 by the formula as followed [28], $\mathrm{N}=(\mathrm{Z} \alpha+\mathrm{Z} \beta)^{2} \times \mathrm{P}(1-$ $\mathrm{P}) / \delta^{2}=(1.63+1.28)^{2} \times 0.8 \times 0.2 / 0.12=136.4224 \approx 136$. And 150 participants for each group were planned to recruited with $10 \%$ lost-follow-up concerning.

\section{Site identification}

This study was conducted at several settings in Beijing, China. The participants were recruited from pediatric clinic department of Beijing Dongfang Hospital, pediatric clinic department of Beijing Dongzhimen Hospital, and Guoyitang TCM clinic department of Beijing University of Chinese Medicine.

\section{Patient recruitment}

We consecutively recruited children according to selection criteria. Children who were eligible for inclusion in our study were those with age $\geq 1$ year old and $\leq 18$ years old and with a history of 3 or more RTI episodes in the past 12 months. Fully informed consent was obtained prior to entry. All participants guaranteed to provide the information needed for the case report form (CRF) and be followed up in the next 12 months.

We excluded children with severe circulatory diseases, nervous diseases, urinary diseases, hematological disease. And we also excluded participants with serious digestive system diseases such as severe gastritis, peptic ulcers, colitis, and those who were involved in other clinical trials.

\section{Ethics}

Research approval was obtained from the Ethics Committee of the Beijing University of Chinese Medicine in March $9^{\text {th }}$, 2012. Written informed consents were given to the parents or other guardians of children participants with well explained by researchers before study.

\section{Data collection}

Standard operating procedures (SOPs) training was given before recruiting to all study personnel as quality control, including sticking to inclusion and exclusion criteria, completing the questionnaires, ensuring the quality of CRFs and discussing strategies for keeping participants compliant. Plain language was used and recruitment strategies were standardized while collecting data; and all the information involved was recorded in CRFs.

The GHRS diagnosis scale was used to allocate the participants to GHRS group or non-GHRS group, which has been developed by using mixed methods including literature analysis, expert consensus and Delphi methodologies [18]. In this cohort study, we distinguished whether the participant with or without GHRS by detecting the symptoms of the latest three months to avoid the recall bias and these data was retrospective. In addition, the unified questionnaires were used in faceto-face interview for data collecting and the researchers have been trained with SOPs. Two researchers with TCM background scored the participants separately, and discussed each case until reaching agreement.

After recruitment, data were collected: (1) demographic characteristics: gender, age, ethnic group, education and career of their parents, home address and contacts (phone number and e-mail address); (2) physiological characteristics: height, weight, body max index (BMI); (3) past medical history: RTI episodes in the past 12 months, allergic history, influenza vaccination history, pneumonia vaccination history, and other medical history; (4) TCM symptoms: main symptoms, feeling of coldness or fever, sweating, sleep quality, diet and appetite, defecating and urinating, body examination through inspecting, listening and palpatory examination, tongue and pulse diagnosis; (5) personal life history: temperament characteristics, eating habits, food preference. We collected data at the break of participants suffering RTIs for RRTI patients, or at least 7 days later all the RTI symptoms disappeared.

We contacted their parents using face-to-face questionnaire survey, via email or phone every 3 months. We collected data which included (1) episodes of RTI during this period of time in very detail, such as clinical diagnosis, TCM diagnosis, laboratory tests, treating, disease course; (2) TCM symptoms; (3) eating habits. All participants were followed-up for next 12 months, and at the end of follow-up we recorded participants' weight and height again. All the information was provided by the close relatives who took care of the children, most of them were mothers of the participants.

An episode of RTI was defined as a child who had been diagnosed with an acute upper respiratory infection (AURI), bronchitis, or pneumonia by a pediatrician [29]. Episode of RRTI was defined as outcome event. RRTI is 
Table 1 Recurrent respiratory infection diagnosis items

\begin{tabular}{llll}
\hline Age (years old) & $\begin{array}{l}\text { Recurrent } \\
\text { respiratory } \\
\text { infections } \\
\text { (times/year) }\end{array}$ & $\begin{array}{l}\text { Recurrent } \\
\text { bronchitis } \\
\text { (times/year) }\end{array}$ & $\begin{array}{l}\text { Recurrent } \\
\text { pneumonia } \\
\text { (times/year) }\end{array}$ \\
\hline $0-2$ & 7 & 3 & 2 \\
$3-5$ & 6 & 2 & 2 \\
$6-14$ & 5 & 2 & 2 \\
\hline
\end{tabular}

characterized by repeated occurrence of RTI within relative period of normalcy in patients. The diagnostic criteria of RRTI were based on the consensus guidelines published by the Chinese Medical Association Pediatrics Branch Breathing Group and the Chinese Journal of Pediatrics editorial board in December 2007 [5] (see Table 1).

\section{Data management and analysis}

Data management and analysis was performed by using EPI version 3.1 and SAS version 9.3 for Windows. We contacted participants if anything unclear appearing in CRFs. Two researchers input data separately and Epidata was used which was qualified to check data consistency automatically. We compared participants' characteristics and discrete clinical signs of children between GHRS group and none GHRS group by using Pearson Chisquare test, or by using Fisher's exact test if the frequencies were small. Wilcoxon rank sum test was used to compare continuous variables between groups. Descriptive statistics such as frequencies or proportions were completed and presented in tables. The morbidity of RTI in overall cohort was calculated, and the morbidity of URTI and LRTI were calculated separately. Relative risk (RR) of RRTIs with corresponding $95 \%$ confidence intervals $(95 \% \mathrm{CI})$ were used as the primary outcome. The independent variables with $\mathrm{P}$ value less than 0.2 during bivariate analysis were selected as the factors for multivariable analysis. Stratified analysis was used based on the different disease and models and we investigated significant and independent predictors of RTIs identified in each level. Multivariable linear regressions were fitted by using a step-by-step elimination technique $\left(\alpha_{\text {in }}=0.05\right.$, $\left.\alpha_{\text {out }}=0.10\right)$ to indentify independent predictors separately. Multivariable binary logistic regressions were fitted by using retrospective elimination techniques $\left(\alpha_{\text {in }}=0.10\right.$, $\left.\alpha_{\text {out }}=0.15\right)$ to indentify independent predictors separately. Association between dependent and independent variables was assessed by using odds ratios $(\mathrm{OR})$ value and $95 \%$ CI. Statistical association was considered significant if the $\mathrm{P}$ value was less than 0.05 .

\section{Results}

Characteristics of the participants

Convenience sample recruiting was developed and we designed the sample size as 167 participants for each group. 334 children were enrolled with approximately $20 \%$ lost-follow-up concerning in practical research, and all of them were followed up for 12 months prospectively. $307(91.92 \%)$ out of 334 completed follow-up and 27 (8.08 \%) children dropped out; 22 (6.59\%) of them were lost and $5(1.56 \%)$ of them refused to continue (see Fig. 1).

$11(3.58 \%)$ children did not suffer from RTI during 12-month follow-up period. 296 (96.42 \%) children suffered at least 1 RTI episode within this period of time, 15 RTIs episodes was the most observed in this study. 4.32 (95 \% CI 4.03-4.61) RTI episodes for each child in 12 months was the average.

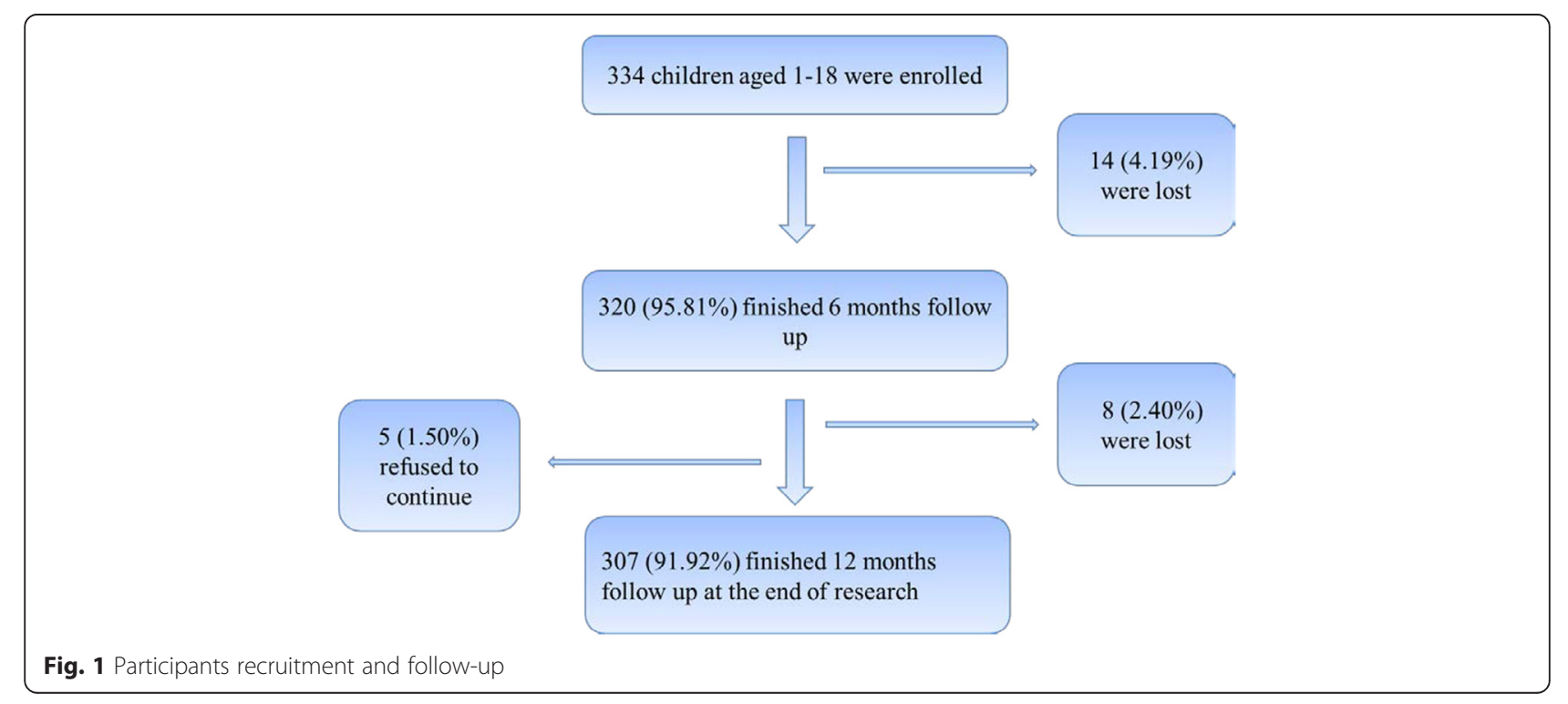




\section{Characteristics of participants in both groups}

The group with GHRS and group without GHRS were distinguished by GHRS scale identification. 160 (52.12 \%) children with GHRS and 147 (47.88 \%) without GHRS were in the observed cohorts.

Table 2 shows the characteristics of the groups and the baseline information from those groups.

It shows that there was no difference $(P>0.05)$ in gender, age, height, weight, ethnic group, character, vaccination against pneumonia, vaccination against flu, and allergic history between two groups, and there was difference $(P<0.05)$ in BMI between two groups.

\section{Occurrence of RTIs and RRTIs in both groups}

Table 3 shows the specific episodes of RTIs during the follow-up visit, and Wilcoxon test were used to compare the RTI episodes between two groups.

Through Wilcoxon test, Z values of RTI episodes in 12 month between the two groups was -3.553 .There was significant difference of RTI occurrence between group with GHRS and group without GHRS $(P=0.000)$.

The morbidity of RRTI in overall cohort was $38.11 \%$. $69(43.13 \%)$ children in the group with GHRS suffered from RRTI; there were 48 (32.65 \%) children in group without GHRS. The risk ratio (RR) value of RRTI occurrence was 1.32 (95\% CI 0.91-1.91, $P=0.139)$, and the attributable risk percent (AR\%) was $24.28 \%$.

\section{Bivariate analysis: linear correlation model}

We built linear correlation models to explore the association between GHRS and RTI (URTI and LRTI) separately. It revealed that GHRS has a linear correlation with RTI over 12 months follow-up (Spearman correlation coefficient $=0.202, P=0.000$ ). GHRS has a linear correlation with URTI over 12 months follow-up (Spearman correlation coefficient $=0.225, P=0.000$ ).

We built linear correlation models to explore correlation between baseline factors, TCM symptoms and RTI episodes. Age (Spearman correlation coefficient $=-0.142, P=0.013$ ), BMI (Spearman correlation coefficient $=-0.143, P=0.012$ ), feverish feeling in palms and soles (Spearman correlation coefficient = $0.165, P=0.004$ ), irritability (Spearman correlation coefficient $=0.117, P=0.041$ ), sleep-talking (Spearman correlation coefficient $=0.142, P=0.013$ ), dry stool (Spearman correlation coefficient $=0.258, P=0.000$ ) and constipation (Spearman correlation coefficient $=0.166, P=0.003$ ) have a linear correlation with RTI episodes.

\section{Multivariate analysis}

\section{Linear regression model}

Multicollinearity between independent variables were checked and not found to be present. Factors had been selected with $\mathrm{P}$ value less than 0.05 in our correlation
Table 2 Characteristics of group with GHRS and group without GHRS

\begin{tabular}{|c|c|c|c|c|}
\hline Characteristics & $\begin{array}{l}\text { Group with GHRS } \\
(N=160) n(\%) / \\
\text { mean }( \pm S D)\end{array}$ & $\begin{array}{l}\text { Group without } \\
\text { GHRS (N=147) } \\
\mathrm{n}(\%) / \text { mean }( \pm \mathrm{SD})\end{array}$ & $x^{2} / Z$ & $P$ value \\
\hline Gender & & & $x^{2}=0.164$ & 0.685 \\
\hline Female & $66(41.25 \%)$ & $64(43.54 \%)$ & & \\
\hline Male & $94(58.75 \%)$ & $83(56.46 \%)$ & & \\
\hline Ethnic group & & & $x^{2}=1.260$ & 0.262 \\
\hline Ethnic Han & 146(91.25 \%) & 139(94.56 \%) & & \\
\hline $\begin{array}{l}\text { Other ethnic } \\
\text { groups }\end{array}$ & $14(8.75 \%)$ & $8(5.44 \%)$ & & \\
\hline Character & & & $x^{2}=0.796$ & 0.672 \\
\hline $\begin{array}{l}\text { Extrovert } \\
\text { personality }\end{array}$ & 113(70.63 \%) & 100(71.43\%) & & \\
\hline Moderate & $35(21.88 \%)$ & $38(27.14 \%)$ & & \\
\hline $\begin{array}{l}\text { Introvert } \\
\text { personality }\end{array}$ & $12(7.50 \%)$ & $9(6.43 \%)$ & & \\
\hline $\begin{array}{l}\text { Vaccination } \\
\text { against } \\
\text { pneumonia }\end{array}$ & & & $x^{2}=9.213$ & 0.010 \\
\hline Yes & 23(14.38 \%) & $9(6.12 \%)$ & & \\
\hline No & $50(31.25 \%)$ & $72(48.98 \%)$ & & \\
\hline Not clear & $87(54.37 \%)$ & $66(44.90 \%)$ & & \\
\hline $\begin{array}{l}\text { Vaccination } \\
\text { against flu }\end{array}$ & & & $x^{2}=2.942$ & 0.230 \\
\hline Yes & $15(9.38 \%)$ & $9(6.12 \%)$ & & \\
\hline No & 63(39.37 \%) & $67(45.58 \%)$ & & \\
\hline Not clear & $82(51.25 \%)$ & $71(48.30 \%)$ & & \\
\hline $\begin{array}{l}\text { Allergic } \\
\text { history }\end{array}$ & & & $x^{2}=1.760$ & 0.185 \\
\hline Yes & $27(16.88 \%)$ & $17(12.14 \%)$ & & \\
\hline No & 133(83.12\%) & 130(87.86 \%) & & \\
\hline $\begin{array}{l}\text { Age at } \\
\text { enrollment } \\
\text { (years) }\end{array}$ & $4.87( \pm 2.15)$ & $5.02( \pm 2.36)$ & $Z=-0.759$ & 0.448 \\
\hline $\begin{array}{l}\text { Height at } \\
\text { enrollment } \\
\text { (meters) }\end{array}$ & $1.11( \pm 0.14)$ & $1.11( \pm 0.16)$ & $Z=-0.043$ & 0.966 \\
\hline $\begin{array}{l}\text { Weight at } \\
\text { enrollment } \\
\text { (kilograms) }\end{array}$ & $20.68( \pm 8.08)$ & $19.74( \pm 7.83)$ & $Z=-1.651$ & 0.099 \\
\hline $\begin{array}{l}\text { BMl at } \\
\text { enrollment } \\
\left(\mathrm{kg} / \mathrm{m}^{2}\right)\end{array}$ & $16.39( \pm 2.54)$ & $15.55( \pm 2.05)$ & $Z=-3.079$ & $0.002^{*}$ \\
\hline
\end{tabular}

model, and multiple linear regression models had been built in terms of those factors. In addition, a step-bystep elimination technique $\left(\alpha_{\text {in }}=0.05, \alpha_{\text {out }}=0.10\right)$ was used to identify the independent variables.

At 12 months follow-up visit, dry stool, age, BMI and irritability were the major variables in the optimal model 
Table 3 RTI episodes in two groups during follow-up visit

\begin{tabular}{|c|c|c|c|c|c|c|}
\hline Follow-up visit period & Disease diagnosis & & Group with GHRS & Group without GHRS & $Z$ value & $P$ value \\
\hline \multirow[t]{4}{*}{3 months } & URTI & & 232 & 179 & -2.478 & $0.013^{*}$ \\
\hline & LRTI & Bronchitis & 16 & 9 & -0.471 & 0.638 \\
\hline & & Pneumonia & 2 & 2 & & \\
\hline & RTI & & 250 & 190 & -2.551 & $0.011^{*}$ \\
\hline \multirow[t]{4}{*}{6 months } & URTI & & 449 & 329 & -3.542 & $0.000^{* *}$ \\
\hline & LRTI & Bronchitis & 29 & 19 & -0.553 & 0.581 \\
\hline & & Pneumonia & 6 & 7 & & \\
\hline & RTI & & 484 & 355 & -3.582 & $0.000^{* *}$ \\
\hline \multirow[t]{4}{*}{9 months } & URTI & & 606 & 441 & -3.990 & $0.000^{* *}$ \\
\hline & LRTI & Bronchitis & 32 & 28 & -0.319 & 0.750 \\
\hline & & Pneumonia & 8 & 8 & & \\
\hline & RTI & & 646 & 477 & -3.710 & $0.000^{* *}$ \\
\hline \multirow[t]{4}{*}{12 months } & URTI & & 723 & 519 & -3.915 & $0.000^{* *}$ \\
\hline & LRTI & Bronchitis & 35 & 34 & -0.240 & 0.811 \\
\hline & & Pneumonia & 9 & 9 & & \\
\hline & RTI & & 767 & 562 & -3.553 & $0.000^{* *}$ \\
\hline
\end{tabular}

${ }^{*} P<0.05$ shows there is significant difference between two groups

${ }^{*} P<0.01$ shows there is highly significant difference between two groups

(Adjusted $\left.R^{2}=0.114\right)$, with $\mathrm{F}$ value was $10.820(P=0.000)$ in the ANOVA test of the model, the linear regression model equation was $y=0.246 \times 1-0.128 \times 2-$ $0.146 \mathrm{x} 3+0.120 \times 4$ ( $\mathrm{y}$ is RTI episodes in 12 months, $\mathrm{x} 1$ is dry stool, $\mathrm{x} 2$ is age, $\mathrm{x} 3$ is BMI, $\mathrm{x} 4$ is irritability) (see Table 4).

The results showed that dry stool, BMI, age, irritability were independent variables for RTI occurrence over 12 months follow-up. Dry stool $(P=0.000)$ and irritability $(P=0.028)$ were positively correlated with RTI episodes, and age $(P=0.022)$ and BMI $(P=0.009)$ were negatively correlated with RTI episodes.

\section{Logistic regression model}

Multicollinearity between independent variables were checked and not found to be present. We built logistic regression model with these factors selected from correlation model with $\mathrm{P}$ value less than 0.2 to explore association among them and RRTI occurrence, and we used retrospective elimination techniques $\left(\alpha_{\text {in }}=0.10, \alpha_{\text {out }}=\right.$ $0.15)$ to identify the independent variables.

Dry stool, age, BMI had been selected as independent variables in the optimal model, the logistic regression model equation was $\operatorname{logit}(\mathrm{P})=2.038+0.412 \times 1-$ $0.117 x 2-0.153 \times 3$ ( $x 1$ is dry stool, $x 2$ is age, $x 3$ is $B M I$ ). The OR value of dry stool was 1.510 (95\% CI 1.200$1.900)$, the OR value of age was 0.858 (95\% CI $0.776-1.019)$, the OR value of BMI was 0.858 (95\% CI 0.763-0.965) (see Table 5).

The results showed that dry stool $(P=0.000)$ was positively correlated with RRTI occurrence, age $(P=0.091)$ and BMI $(P=0.011)$ were negatively correlated with RRTI occurrence.

\section{Discussion}

The results suggested that more RTI episodes were reported in the GHRS group than the group without GHRS significantly $(P<0.05)$. It showed there might be

Table 4 Associated factors selected in linear regression model

\begin{tabular}{|c|c|c|c|c|c|}
\hline & \multicolumn{2}{|c|}{ Unstandardiazed coefficients } & \multirow{2}{*}{$\begin{array}{l}\text { Standardiazed coefficients } \\
\text { Beta }\end{array}$} & \multirow[t]{2}{*}{ t value } & \multirow[t]{2}{*}{$P$ value } \\
\hline & Beta & Std. error & & & \\
\hline Constant & 6.361 & 1.002 & & 6.347 & 0.000 \\
\hline Dry stool & 0.608 & 0.133 & 0.246 & 4.569 & 0.000 \\
\hline Age & -0.147 & 0.064 & -0.128 & -2.296 & 0.022 \\
\hline BMI & -0.160 & 0.061 & -0.146 & -2.643 & 0.009 \\
\hline Irritability & 0.299 & 0.135 & 0.120 & 2.211 & 0.028 \\
\hline
\end{tabular}


Table 5 Associated factors screened in logistic regression model

\begin{tabular}{llllll}
\hline & B & P value & OR value & \multicolumn{2}{c}{$95 \% \mathrm{Cl}$ of OR value } \\
\cline { 5 - 6 } & & & & Lower & Upper \\
\hline Dry stool & 0.412 & 0.000 & 1.510 & 1.200 & 1.900 \\
Age & -0.117 & 0.091 & 0.889 & 0.776 & 1.019 \\
BMl & -0.153 & 0.011 & 0.858 & 0.763 & 0.965 \\
Constant & 2.038 & 0.038 & 7.676 & & \\
\hline
\end{tabular}

positive association between GHRS and RRTI. As GHRS was a predictive factor, we could not deduce the causeeffect association between GHRS and RRTI. However, the association between GHRS and RRTI could be implied according to TCM theory [13].

Confounding factors were controlled in this study. All participants were aged from 1 to 18 without other underlying disease. The TCM diagnosis of participants were made by doctors with over 20 years clinical TCM experience. This research was conducted in unblinded real-world medical settings and all the data were acquired in clinical environment. The doctors who made TCM diagnosis did not take part in follow-up visits, and researchers who collected medical records in follow-up visits did not know exactly which group the participant belonged to. Therefore, blinding method was used in the data collecting and analyzing processes. Furthermore, there might be data missing during the follow up caused by recall bias in the cohort study, even though we collected data every 3 months, and participant booklets and medical record books were collected to compensate, which were used to record the sufferings and treatment in very detail by participants' parents and the practitioners. There may be some bias caused by different investigators scoring the GHRS scale.

Two models had been built in this study to explore independent factors which were associated with RRTI. Dry stool was positively associated with RRTI, while age and BMI were negatively associated with RRTI. The results showed that there was a positive correlation between the extent of dry stool and RTIs in children, and extension of defecation time interval was positively correlated with RTIs as well. This study also suggested that BMI was negatively correlated with RTIs. Low BMI might due to prolonged GHRS which could impact digestive system function. TCM practitioners have realized that younger children are more prone to catching GHRS, especially the kindergarten children who are aged from 3 to 6 years old [13]. Therefore, it is necessary to explore how these factors including age, diet, BMI may contribute to the development of GHRS in the further research.

The findings of this prospective cohort study will be meaningful for TCM practitioners when treating RRTI children with GHRS. We have been suggesting that GHRS may be an important internal cause to catch
RTIs, especially for children, for living standards have been greatly improved in China, and there are more food choices which are available for children. An unbalanced diet, such as rich in sugar, protein, energy, salt or additives, all above are difficult to be digested and absorbed effectively for children, which may lead to a GHRS thus predisposing to RRTI. Furthermore, GHRS may be ignored by practitioners and parents, while which is supposed to be considered as a predisposing factor.

TCM theories may help us understand the aetiology of chronic illness. This is a prospective cohort study that identified an association between GHRS and RRTI that should be tested prospectively. And a Grounded Theory study has been conducted to induce and generalize a theory by concerning and processing raw data from the perspectives of TCM practitioners' understandings and experiences towards the interaction between GHRS and RRTI to theorize the results of this cohort study. Studies with larger sample size and longer follow up are needed in the future.

\section{Conclusions}

There was association between GHRS and RRTI. We found that dry stool and BMI were the factors which impacted most, and dry stool was positively associated with RRTI, BMI was negatively associated with RRTI. Studies with larger sample size and longer follow up are needed in the future to further evaluate this association. Relieving GHRS symptoms should be considered when practitioners treating RRTI children with GHRS.

\section{Abbreviations}

AR\%: attributable risk percent; ARTI: acute respiratory tract infection;

AURI: acute upper respiratory infection; BMI: body max index; Cl: confidence intervals; CRF: case report form; FM1: A/Fort Monmouth/1/47(H1N1);

GHRS: gastrointestinal heat retention syndrome; LRTI: lower respiratory tract infection; OR: odds ratios; RR: relative risk; RRTI: recurrent respiratory tract infection; RTI: respiratory tract infection; SOP: standard operating procedure; TCM: Traditional Chinese Medicine; URTI: upper respiratory tract infection.

\section{Competing interests}

The authors declare that they have no competing interests.

\section{Authors' contributions}

$X G, H Y, F D, L W$ and JM contributed to study design, conceived of the study. $F D, H Y, J M, L W$, TL, Guokai LV, JZ, and XL performed the cohort research and contributed to data collection. FD, HY and JM were in charge of data managing and data inputing. FD, HY, JM and TL analyzed data. GL helped with manuscript drafting and revising and helped with the language. FD and HY were equally principal authors of the paper, had full access to all data. All authors contributed to the manuscript drafting and revising and approved the final manuscript.

\section{Acknowledgements}

We would like to express our gratitude to all the participants and their families to provide the information in this study. And this study was funded by the National Natural Science Foundation of China (NO.81273994) and Beijing Educational Committee cooperation projects (NO.1000062520115), both of them are hosted by Prof. Xiaohong Gu. 


\section{Author details}

'School of Basic Medical Science, Beijing University of Chinese Medicine, Beijing, China. ${ }^{2}$ Beijing Hospital of Traditional Chinese Medicine, Beijing, China. ${ }^{3}$ Dongfang Hospital Affiliated to Beijing University of Chinese Medicine, Beijing, China. ${ }^{4}$ Beilun Hospital of Chinese Medicine, Ningbo City, China. ${ }^{5}$ Complementary and Integrated Medicine Research Unit, Primary Care and Population Sciences, Southampton University, Southampton, UK.

\section{Received: 14 October 2015 Accepted: 19 February 2016}

Published online: 27 February 2016

\section{References}

1. Hardelid P, Dattani N, Cortina-Borja M, Gilbert R. Contribution of respiratory tract infections to child deaths: a data linkage study. BMC Public Health. 2014;14:1191.

2. Williams B, Gouws E, Boschi-Pinto C, Bryce J, Dye C. Estimates of world-wide distribution of child deaths from acute respiratory infections. Lancet Infect Dis. 2002:2:25-32.

3. Zhou W, Lin F, Teng L, Li H, Hou J, Tong R, et al. Prevalence of herpes and respiratory viruses in induced sputum among hospitalized children with non-typical bacterial community-acquired pneumonia. PLoS One. 2013;8, e79477.

4. van den Aardweg MTA, Boonacker CWB, Rovers MM, Hoes AW, Schilder AGM Effectiveness of adenoidectomy in children with recurrent upper respiratory tract infections: open randomised controlled trial. BMJ. 2011;343:d5154

5. Xia W. The clinical concept and management principles of recurrent respiratory tract infections in 2007. In: MD Weekly. vol. 6; 2008. (in Chinese)

6. Shoucheng W. Pediatrics of Chinese Medicine. Beijing: Chinese Press of Traditional Chinese Medicine; 2012 (in Chinese).

7. Wenjie X, Weihong L, Yixun Z, Huina Z, Jun Z, Dandan D, et al. The survey of recurrent respiratory tract infections morbidity and influence factors in 3-6 years old children in Beijing Chaoyang District. Beijing Journal of Traditional Chinese Medicine. 2011;30(4):258-61 (in Chinese).

8. Weihong L, Wenjie $X$, Huina Z, Guozhong L, Jun Z, Dandan D, et al. The survey of recurrent respiratory tract infections morbidity and influence factors in 3-6 years old children in Beijing Pinggu District. Journal of Capital Medical University. 2011:32(3):431-5 (in Chinese).

9. Javier D, Eduaro GP, Jose AM, Manuel S, Maria DA, Antonio JB, et al. Social, economic, and health impact of the respiratory syncytial virus: a systematic search. BMC Infect Dis. 2014;14:544

10. Singh M. Recurrent Lower Respiratory Tract Infections in Children. Indian J Pediatr. 1999;66:887-93.

11. Pinnock CB, Douglas RM, Badcock NR. Vitamin A status in children who are prone to respiratory tract infections. Journal of Paediatrics and Child Health. 1986;2(22):95-9.

12. Shumin $Z$, Ling $X$, Shulan $P$, Baodong $P$, Lihua $C$. The risk factors analysis of children recurrent respiratory infection. Maternal \& Child Health Care of China. 2012;27(4):536-8 (in Chinese)

13. Wang Z. Influence of Yinlai Tang on immunity in mice with dyspepsia combining influenza virus infection. China: Beijing University of Chinese Medicine; 2013 (in Chinese).

14. Li C, Ping G. The treatment of susceptible children should give priority to aid digestion. Journal of Jilin Chinese Medicine. 2005;25(4):11 (in Chinese).

15. Liping S, Yanbo W. A clinical study: Jianerqingjie decoction combined with Guasha treating 79 children with recurrent respiratory tract infections. Journal of Chinese integrative medicine pediatrics. 2010;2(3):201-3 (in Chinese).

16. Shuping $H, Y u e Z$. The treatment on 68 children with recurrent respiratory tract infections based on lung and stomach heat. Journal of Tianjin Chinese Medicine. 2007;24(5):373-4 (in Chinese)

17. Guokai L, He Y, Fei D, Fei T, Quanyue X, Xueyan M, et al. Research progress of gastrointestinal heat retention syndrome. J Zhejiang Univ Chin Med. 2014:10:1241-1244+1248. in Chinese.

18. Guokai $L$. The research on diagnosis scale of gastrointestinal heat retention syndrome and its reliability and validity of evaluation. China: Beijing University of Chinese Medicine; 2014 (in Chinese).

19. Youssef N. Childhood constipation:evaluation and treatment. J Clin Gestroenterol. 2001;20(5):49-50.

20. Yamei H, Zaifang J. Zhu Futang practical pediatrics. Beijing: People's Medical Publishing House; 2002 (in Chinese).
21. Yilin C. A clincal study on treating infantile constipation dyspepsia by heat-purging, intestine-moistening and stagnancy-removing method. China: Nanjing University of Chinese Medicine; 2013 (in Chinese).

22. Zhongxia $\mathbf{W}$. The theory and clinical research progress on lung and large intestine close connection. Beijing Journal of Traditional Chinese. 2006;25(7):438-40. in Chinese.

23. Jinda W. The clinical study and essential discussion of the theroy 'lung and large intestine close connection 'in traditional Chinese medicine. Chinese Journal of Integrative Medicin. 1982;2:77 (in Chinese).

24. Xuerui $F$. The experimental research of'lung and large intestine close connection. Beijing Journal of Traditional Chinese. 1988:4:16 (in Chinese).

25. Chuhui R. A clinical research on constipation and oliguria in patients with Wind-warm Lung-heat Disease and of phlegm-heat accumulated in chest syndrome. Zhejiang Jounarl of Integrative Medicine. 2007;17(5):290 (in Chinese).

26. Xiaozheng D, Liang L, Xiaochun F. Clinical experience of Pro. Feng Xiaochun treating infantile constipation. Chinese integrative medicine pediatrics. 2012:4(5):393-4 (in Chinese).

27. Xiaohong G, He Y. Influence of Yinlai Decoction on serum IL-2 and TNF-a levels in mice with lung-stomach heat retention syndrom. Journal of Beijing University of Traditional Chinese Medicine. 2008;31(1):54-7 (in Chinese).

28. Jialiang W. Clinical Epidemiology. Beijing: People's Medical Publishing House; 2006 (in Chinese).

29. Weiping W. Pediatrics. Beijing: People's Medical Publishing House; 2008 (in Chinese)

\section{Submit your next manuscript to BioMed Central and we will help you at every step:}

- We accept pre-submission inquiries

- Our selector tool helps you to find the most relevant journal

- We provide round the clock customer support

- Convenient online submission

- Thorough peer review

- Inclusion in PubMed and all major indexing services

- Maximum visibility for your research

Submit your manuscript at www.biomedcentral.com/submit
) Biomed Central 